\title{
Liquid crystalline cyclohexene and cyclohexane derivatives and the compositions based upon them
}

\author{
V. S. Bezborodov,* V. I. Lapanik, and G. M. Sasnouski \\ Institute of Applied Physics Problems, Minsk 220064, Belarus \\ E-mail: v_bezborodov@yahoo.com
}

\section{Dedicated to Prof. Oleg Kulinkovich on the occasion of his 60th birthday}

\begin{abstract}
The synthesis and chemical transformations of 3, 6-disubstituted cyclohex-2-enones into new liquid crystalline cyclohexene and cyclohexane derivatives are discussed. 3, 6-Disubstituted cyclohex-2-enones have been synthesized by the condensation of appropriate 2-bromoethyl ketones with the 4-substituted benzylmethyl ketones or 2-substituted acetoacetic esters.
\end{abstract}

Keywords: 1-(trans-4-Alkylcyclohexyl)cyclopropanols, 3,6-disubstituted cyclohex-2-enones, liquid crystalline compounds and materials

\section{Introduction}

The mesomorphic derivatives of cyclohexylbenzene and trans, trans-dicyclohexylbenzene are very useful in LC mixtures because they have low melting points and a low viscosity of their smectic or nematic phases, allowing one to prepare mesomorphic compositions for different kinds LC Displays. ${ }^{1-5}$ Unfortunately, the synthetic routes to such compounds are usually multistage and need low temperatures or an inert atmosphere, Grignard coupling of 4alkylcyclohexanones and 4-(trans-4-alkylcyclohexyl)cyclohexanones.

We have recently reported that different liquid crystalline cyclohexane, cyclohexene derivatives can be easily prepared from appropriate 3,6-disubstituted cyclohex-2-enones. ${ }^{6-9}$ In this paper we describe continued investigations of 3,6-disubstituted cyclohex-2-enones and show how these compounds can be used for the synthesis of both well know and new liquid crystalline derivatives of trans, trans-dicyclohexylbenzene, trans-cyclohexylcyclohexenylbenzene, 1,4disubstituted cyclohexenes or trans-1,4-cyclohexanes, having $\mathrm{CH}_{2} \mathrm{CH}_{2}$ bridge fragment. We have investigated their mesomorphic properties and the physical and electro-optical properties of 
LC compositions based upon them; the results are summarized here, emphasizing structureproperty relations.

\section{Results and Discussion}

We have described an approach to preparing liquid crystalline (LC) compounds using Michael condensation of the corresponding Mannich salts with 2-substituted acetoacetic esters or substituted benzylmethyl ketones. ${ }^{10}$ For the preparation of LC compounds possessing trans, trans-dicyclohexyl and trans-cyclohexylcyclohexenyl cores, we have used a new synthetic pathway because the analogous salts cannot be prepared from trans-1-acetyl-4-sustituted cyclohexanes or alkylmethylketones in yields higher than $50 \%$ and some of these products are very difficult to isolate by crystallization from the reaction mixture. The reaction of Grignard reagents with ethyl trans-4-alkylcyclohexane-1-carboxylates $\mathbf{1}$ in the presence of tetraisopropoxytitanium leads in high yields (more than 90\%) to 1-(trans-4alkylcyclohexyl)cyclopropanols 2 . This was the key stage in the new procedure (Scheme 1). ${ }^{11}$ These compounds with bromine in methanol are easily transformed into 2-bromoethyl ketones $\mathbf{3}$ (yield more than 90\%), which are the precursors of trans-4-alkylcyclohexylvinylketones used instead of Mannich salts in the condensation with 4-substituted benzylmethyl ketones or 2substituted acetoacetic esters. Using the 2-bromoethylketones $\mathbf{3}$ and 4-substituted benzylmethyl ketones 4 or 2-substituted acetoacetic esters 7, 10 we synthesized 3,6-disubstituted cyclohex-2enones 5, 8, 11 (Table 1) in yields 60-70\%. Catalytic hydrogenation of these products in the presence of $10 \%$ palladium on charcoal and potassium hydroxide in THF-methanol yields the corresponding trans-2,5-disubstituted cyclohexanones 6, 9, 12 (Table 2).

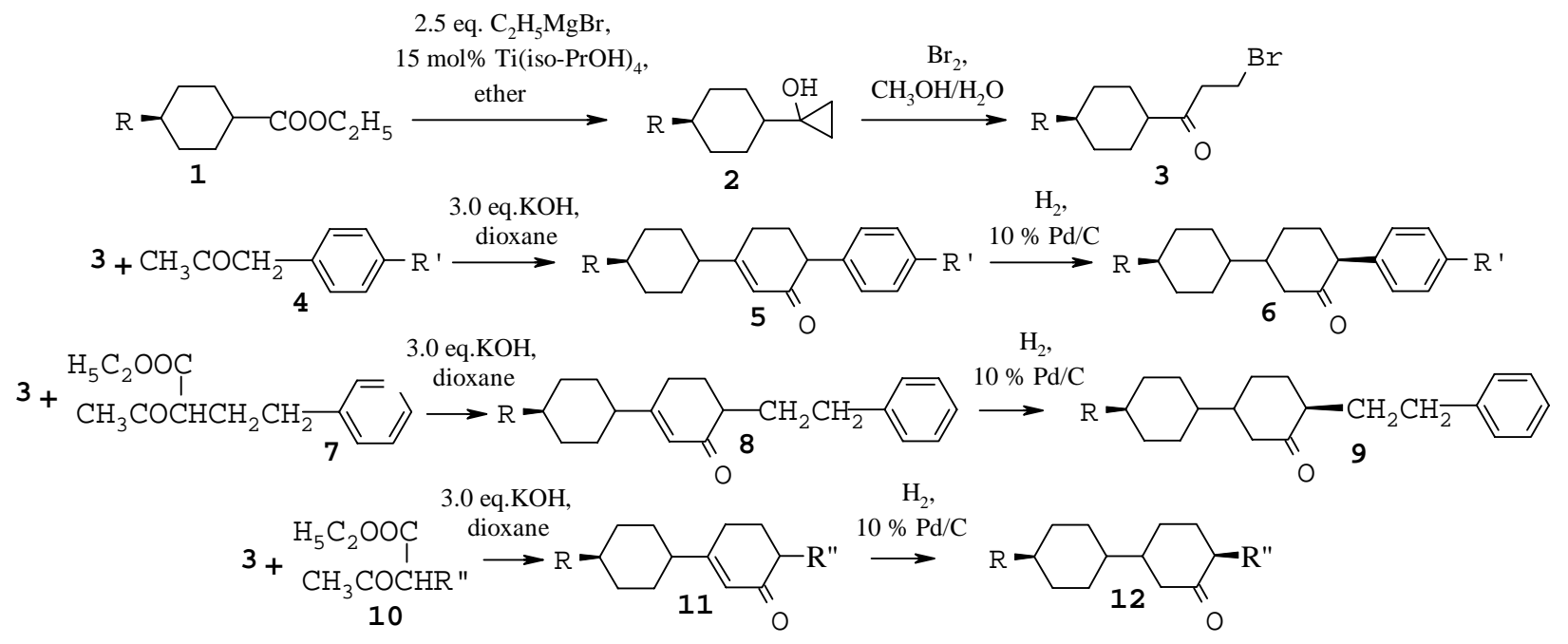

$\mathrm{R}=\mathrm{C}_{3} \mathrm{H}_{7}-\mathrm{C}_{5} \mathrm{H}_{11} ; \mathbf{R}^{\prime}=\mathrm{F} ; \mathrm{OCH}_{3} ; \mathrm{Cl} ; \mathrm{C}_{3} \mathrm{H}_{7} ; \mathrm{R}^{\prime \prime}=\mathrm{C}_{3} \mathrm{H}_{7}, \mathrm{C}_{5} \mathrm{H}_{11}, \mathrm{CH}_{2} \mathrm{CH}_{2} \mathrm{CN}$

Scheme 1 
Table 1.Yields and transition temperatures of 3, 6-disubstituted cyclohex-2-enones 5

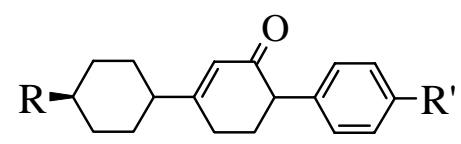

\begin{tabular}{ccccccccc}
\hline $\mathrm{N}$ & \multirow{2}{*}{$\mathrm{R}$} & $\mathrm{R}{ }^{\prime}$ & Yield, \% & \multicolumn{5}{c}{ Transition temperatures $/{ }^{\circ} \mathrm{C}^{(*)}$} \\
\cline { 5 - 8 } & & & & $\mathrm{Cr}$ & $\mathrm{N}$ & \multicolumn{3}{c}{$\mathrm{I}$} \\
\hline $\mathrm{a}$ & $\mathrm{C}_{3} \mathrm{H}_{7}$ & $\mathrm{~F}$ & 56 & $\bullet$ & - & 105 & $\bullet$ \\
$\mathrm{b}$ & $\mathrm{C}_{3} \mathrm{H}_{7}$ & $\mathrm{OCH}_{3}$ & 55 & $\bullet$ & $(80)$ & $\bullet$ & 95 & $\bullet$ \\
$\mathrm{c}$ & $\mathrm{C}_{5} \mathrm{H}_{11}$ & $\mathrm{~F}$ & 55 & $\bullet$ & - & 107 & $\bullet$ \\
$\mathrm{d}$ & $\mathrm{C}_{5} \mathrm{H}_{11}$ & $\mathrm{Cl}$ & 48 & $\bullet$ & - & 103 & $\bullet$ \\
$\mathrm{e}$ & $\mathrm{C}_{5} \mathrm{H}_{11}$ & $\mathrm{OCH}_{3}$ & 52 & $\bullet$ & - & 106 & $\bullet$ \\
$\mathrm{f}$ & $\mathrm{C}_{5} \mathrm{H}_{11}$ & $\mathrm{C}_{3} \mathrm{H}_{7}$ & 54 & $\bullet$ & - & 104 & $\bullet$ \\
\hline
\end{tabular}

${ }^{(*)}$ - presence of phase state, - absence of phase state.

Table 2.Yields and transition temperatures of trans-2, 5-disubstituted cyclohexanones 6

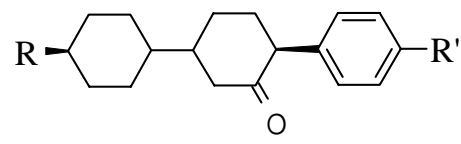

\begin{tabular}{|c|c|c|c|c|c|c|c|c|}
\hline \multirow[t]{2}{*}{$\mathrm{N}$} & \multirow[t]{2}{*}{$\mathrm{R}$} & \multirow[t]{2}{*}{$\mathrm{X}$} & \multirow{2}{*}{$\begin{array}{c}\text { Yield, } \\
\%\end{array}$} & \multicolumn{5}{|c|}{ Transition temperatures $/{ }^{\circ} \mathrm{C}$} \\
\hline & & & & $\mathrm{Cr}$ & & $\mathrm{N}$ & & I \\
\hline $\mathrm{a}$ & $\mathrm{C}_{3} \mathrm{H}_{7}$ & $\mathrm{~F}$ & 82 & $\bullet$ & 107 & $\bullet$ & 122 & $\bullet$ \\
\hline $\mathrm{b}$ & $\mathrm{C}_{3} \mathrm{H}_{7}$ & $\mathrm{OCH}_{3}$ & 72 & $\bullet$ & 105 & $\bullet$ & 178 & $\bullet$ \\
\hline
\end{tabular}

Unfortunately, unlike the condensation of trans-4-alkylcyclohexyl-2-bromoethylketone with 2-alkylacetoacetic esters, the interaction of bis-2-bromoehylketone 14 with 2-propylacetoacetic ester in the presence of potassium hydroxide (Scheme 2) does not proceed well in the required direction and leads to the formation of the diketone 15 in low yield (about 10\%). 


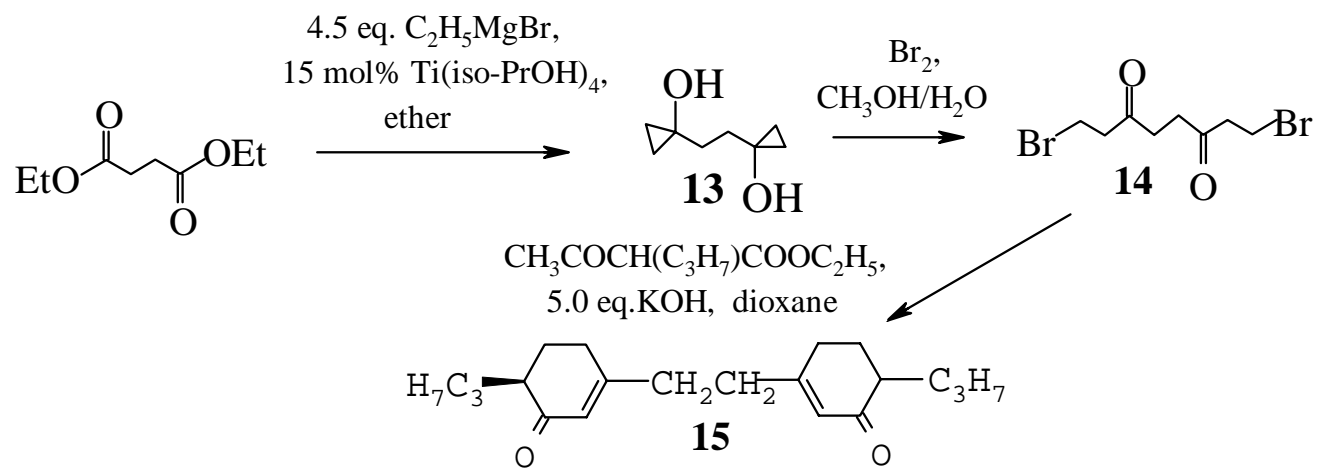

\section{Scheme 2}

The trans-2, 5-disubstituted cyclohexanones 6, 9, 12 are perspective intermediates for the synthesis of well known liquid crystalline trans-1, 4-disubstituted cyclohexanes, which are formed by Wolf-Kishner reduction of these ketones. However, the most interesting direction for the further chemical transformations of trans-2,5-disubstituted cyclohexanones $\mathbf{6 , 1 2}$ is their interaction with diethylaminosulfur trifluoride (DAST) or with sodium borohydride, as a result of which the the corresponding liquid crystalline gem-difluoroderivatives 16, 18 or alcohols 19 are formed. The difluroderivatives and alcohols can be converted into 2, 5-disubstituted 1fluorocyclohex-1-enes and/or 1, 4-disubstituted cyclohex-1-enes 17, 20 (Scheme 3), are characterized by low melting points, and a wide temperature range of nematic phase (Table 3). They are therefore promising components of LC mixtures for different types of displays.

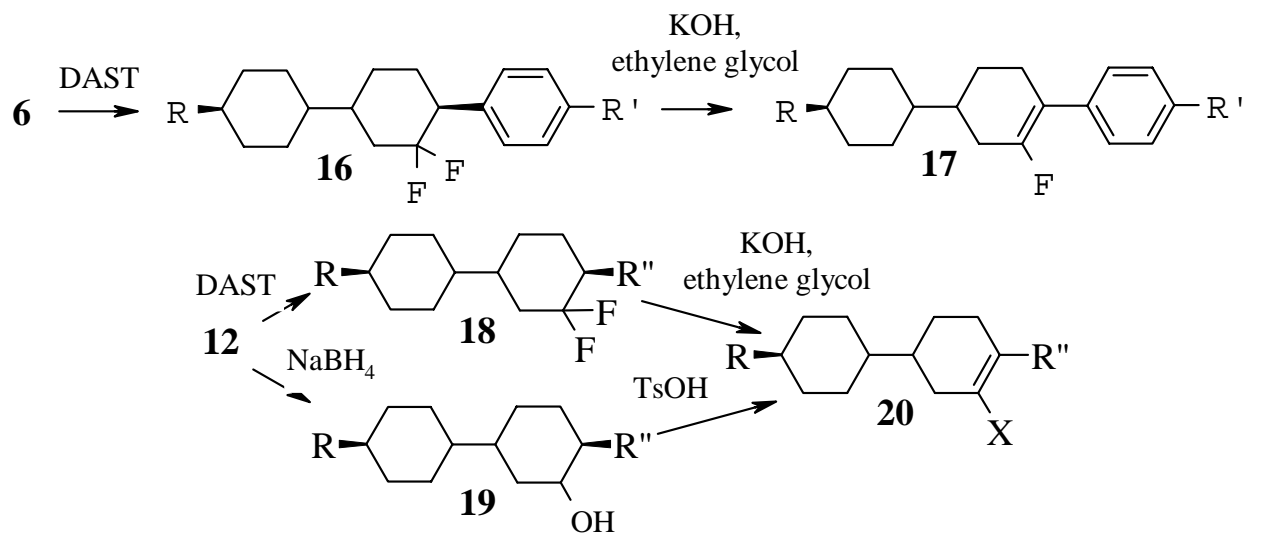

\section{Scheme 3}


Table 3. Yields and transition temperatures of 2, 5-disubstituted 1-fluorocyclohex-1-enes 17

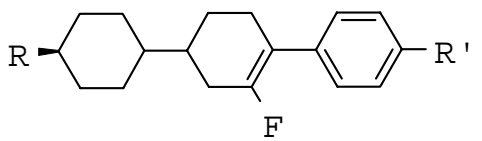

\begin{tabular}{|c|c|c|c|c|c|c|c|c|c|c|}
\hline \multirow[t]{2}{*}{$\mathrm{N}$} & \multirow[t]{2}{*}{$\mathrm{R}$} & \multirow[t]{2}{*}{$\mathrm{R}^{\prime}$} & \multirow[t]{2}{*}{ Yield, \% } & \multicolumn{7}{|c|}{ Transition temperatures $/{ }^{\circ} \mathrm{C}$} \\
\hline & & & & $\mathrm{Cr}$ & & $\mathrm{Sm}$ & & $\mathrm{N}$ & & I \\
\hline $\mathrm{a}$ & $\mathrm{C}_{3} \mathrm{H}_{7}$ & $F$ & 25 & - & 33 & - & & & 122 & • \\
\hline $\mathrm{b}$ & $\mathrm{C}_{3} \mathrm{H}_{7}$ & $\mathrm{OCH}_{3}$ & 25 & & 56 & - & & & 188 & • \\
\hline C & $\mathrm{C}_{5} \mathrm{H}_{11}$ & $\mathrm{~F}$ & 28 & & 34 & - & & & 129 & • \\
\hline $\mathrm{d}$ & $\mathrm{C}_{5} \mathrm{H}_{11}$ & $\mathrm{OCH}_{3}$ & 24 & & 53 & - & & & 188 & . \\
\hline $\mathrm{e}$ & $\mathrm{C}_{5} \mathrm{H}_{11}$ & $\mathrm{C}_{3} \mathrm{H}_{7}$ & 54 & $\bullet$ & 38 & $\bullet$ & 120 & $\bullet$ & 144 & 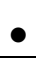 \\
\hline
\end{tabular}

Cyclohexanones $\mathbf{9}$ are also prospective intermediates for the synthesis of liquid crystalline compounds with promising properties. By the modification of these ketones using the acetylation and subsequent transformation of acetyl derivatives 21 according to the scheme 4, we prepared the cyclohexenes (23), which are characterized by low temperature formation of mesophase with wide temperature ranges.

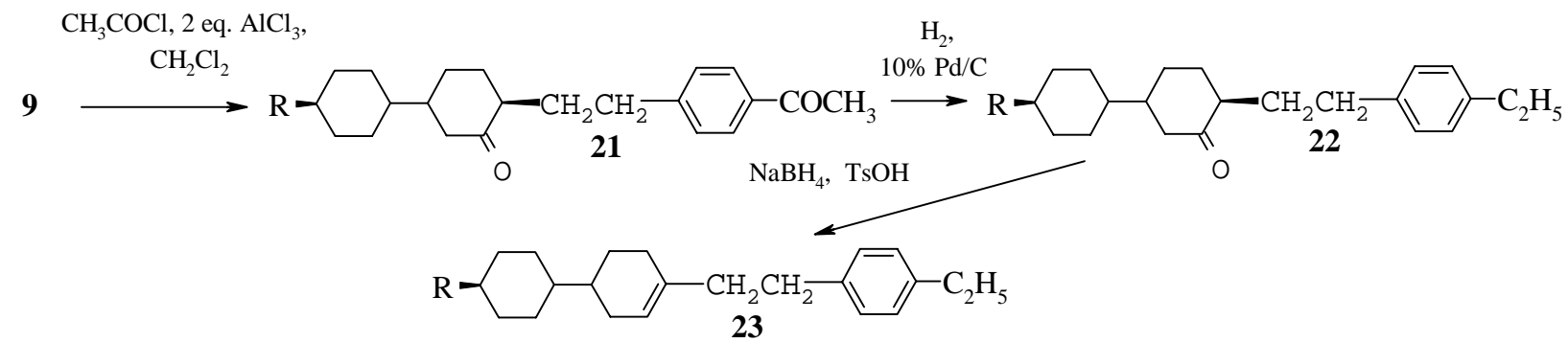

\section{Scheme 4}

The proton NMR spectra $(\delta$, ppm) of 3, 6-disubstituted cyclohex-2-enones 5, 8, 11 showed that the multiplet at 5.81-5.85 or $6.25-6.43$ belongs to the proton located at the double bond of the cyclohexenone fragment. Two triplets at 2.20-2.39 in the proton NMR spectra of the saturated ketones 6, 9, 12 correspond to the protons in the cyclohexanone fragment. The multiplet at 5.45-5.69 in the spectra of the cyclohexene derivatives 20, 23 belongs to the protons located at the double bond of cyclohexene fragments. The signals from protons of the cyclohexane fragment of difluoroderivatives 16, 18 are observed in the spectra in the form of triplets at 2.43 and 2.82. The signals at $1.30-2.82$ in the NMR spectra of fluorocyclohexenes 17 belong to protons of the cyclohexane and cyclohexene fragments. 
Investigations of the electro-optical and dynamic parameters of LC mixtures containing synthesized 2,5-disubstituted 1-fluorocyclohex-1-enes and/or 1,4-disubstituted cyclohex-1-enes 17, 20, 23 have shown that these compounds are promising components of the materials for $240^{0}$ twist STN-displays, multiplexed $2^{\text {nd }}$ minimum TN-displays and active matrix addressed displays. These allow the threshold voltage and the steepness parameter of the voltage-contrast curve to be decreased, and also to verify the optical anisotropy of the nematic mixtures without significant changes in other parameters. Using the cyclohexene derivatives we have prepared LC compositions with good dynamic parameters for high level multiplexed $2^{\text {nd }}$ minimum TNdisplays and active matrix addressed displays. For $240^{\circ}$ twist STN-displays we have developed new mixtures which are characterized by a wide temperature range of the nematic phase $\left(-40^{\circ} \mathrm{C}\right.$ $+100^{\circ} \mathrm{C}$ ), a low temperature dependence of the threshold voltage and a small sharpness parameter $\left(\mathrm{P}_{10-90}=0.03-0.022 ; \mathrm{N}_{10-90}=1120\right.$ - 2000).

\section{Experimental Section}

General Procedures. Confirmation of the structures, all intermediates and the final products was obtained using a GC/MS mass-spectrometer (HP 5972 MSD) and ${ }^{1} \mathrm{H}$ NMR spectroscopy. The purity of the compounds was checked using a HP 5890 capillary gas chromatograph fitted with a HP1 column.

Phase transition temperatures were measured using a Linkam heating stage in conjugation with polarising PZO microscope and also by differential scanning calorimetry (Setaram DSC 92).

The measurements of the electrooptic patameters of the mixtures were performed at room temperature in twisted nematic cells with $6 \mu \mathrm{m}$ spacers, a polyamide layer to obtain homogeneously oriented samples.

\section{Synthesis of 1-(trans-4-alkylcyclohexyl)-1-cyclopropanols (2). General procedure}

The Grignard reagent prepared in the usual way from $6.0 \mathrm{~g}(0.25 \mathrm{~mol})$ of magnesium and 0.25 mol of ethyl bromide was slowly added during $2 \mathrm{~h}$ at room temperature to vigorously stirred solution of $0.1 \mathrm{~mol}$ of ethyl trans-4-alkylcyclohexanecarboxylate and $0.02 \mathrm{~mol}$ (20 mol.\%) of tetraisopropoxytitanium in $100 \mathrm{ml}$ of dry ether. Reaction mixture having brown colour was then stirred additionally at room temperature during $1 \mathrm{~h}$ and decomposed with the cold $10 \%$ solution of sulphuric acid. After washing with water and drying over magnesium sulphate the solvent was removed. The prepared this way 1-(trans-4-alkylcyclohexyl)-1-cyclopropanol just after removing of the solvent had the purity of about 95\% and can be used in next transformation without any additional purification. The yield of cyclopropanols was almost quantitative.

\section{Synthesis of trans-4-alkylcyclohexyl $\boldsymbol{\beta}$-bromoethyl ketones (3). General procedure}

1-(trans-4-Alkylcyclohexyl)-1-cyclopropanol was dissolved in $100 \mathrm{ml}$ of methanol and $5 \mathrm{ml}$ of water. $0.1 \mathrm{~mol}$ of bromine then was added drop wise during $15 \mathrm{~min}$ at room temperature. Slightly 
coloured solution was diluted with water and the product was twice extracted with methylene chloride. The solvent was removed in vacuum and $\beta$-bromoketone was then used without additional purification. The yield is more than $90 \%$.

Synthesis of 3-(trans-4-alkylcyclohexyl)-6-(4-substituted phenyl) cyclohex-2-en-1-ones (5). General procedure

The prepared $\beta$-bromoketone was mixed with 4-substituted benzyl methyl ketone (0.1 mol) and $0.3 \mathrm{~mol}$ of potassium hydroxide in $150 \mathrm{ml}$ of dioxane and resulting mixture was refluxed under stirring during $5 \mathrm{~h}$. After cooling and treatment with 10\% solution of sulphuric acid the product was twice extracted with methylene chloride. After drying over sodium sulphate and removing of the solvent the ketone has been twice crystallised from ethanol.

3-(trans-4-Propylcyclohexyl)-6-(4-fluorophenyl) cyclohex-2-en-1-ones (5a). Yield 56\%. m.p. $105^{0} \mathrm{C}$. MS (70 eV) m/z (\%): 314 (M , 51); 270 (20), 189 (75), 177 (30), 162 (80), 134 (95), 121 (55), 109 (30), 95 (15), 69 (25), 55 (35), 41 (50), 29 (15). Purity (GC) > 98\%. Anal. Calcd for $\mathrm{C}_{21} \mathrm{H}_{27}$ FO: C 80.25, H 8.60. Found: C 80.41, H 8.47.

3-(trans-4-Propylcyclohexyl)-6-(4-methoxyphenyl) cyclohex-2-en-1-ones (5b). Yield 55\%. m.p. $95^{\circ}$ C. Purity (GC) $>98 \%$. Anal. Calcd for $\mathrm{C}_{22} \mathrm{H}_{30} \mathrm{O}_{2}$ : C 80.98, H 9.20. Found: C 81.15, H 9.07.

3-(trans-4-Pentylcyclohexyl)-6-(4-fluorophenyl) cyclohex-2-en-1-ones (5c). Yield 55\%. m.p. $107^{0} \mathrm{C}$. MS (70 eV) m/z (\%): 342 ( $\left.\mathrm{M}^{+}, 51\right) ; 300$ (30), 205 (15), 189 (65), 162 (55), 146 (30), 133 (85), 121 (30), 109 (35), 55 (20), 41 (35), 29 (20). Purity (GC) > 98\%. Anal. Calcd for $\mathrm{C}_{23} \mathrm{H}_{31}$ FO: C 80.70, H 9.06. Found: C 80.91, H 9.23.

3-(trans-4-Pentylcyclohexyl)-6-(4-chlorophenyl) cyclohex-2-en-1-ones (5d). Yield 48\%. m.p. $103^{0} \mathrm{C}$. MS (70 eV) m/z (\%): 358 (M , 75); 220 (70), 192 (20), 177 (25), 149 (95), 138 (50), 110 (75), 95 (60), 79 (70), 55 (35), 41 (65). Purity (GC) > 98\%.

3-(trans-4-Pentylcyclohexyl)-6-(4-methoxyphenyl)cyclohex-2-en-1-ones (5e). Yield 52\%. m.p. $106^{0} \mathrm{C}$. Purity (GC) > 98\%. Anal. Calcd for $\mathrm{C}_{24} \mathrm{H}_{34} \mathrm{O}_{2}$ : C 81.35, H 9.60. Found: C 81.53, H 9.80.

\section{trans-2-( trans-4-Alkylcyclohexyl)-5-(4-substituted phenyl)cyclohexanone (6). General procedure}

3-(trans-4-Alkylcyclohexyl)-6-(4-substituted phenyl)cyclohex-2-en-1-one (0.01 mol) in $150 \mathrm{ml}$ THF containing $0.5 \mathrm{~g}$ potassium hydroxide was hydrogenated with energetic stirring at room temperature in the presence of $1.0 \mathrm{~g} 10 \%$ palladium on carbon. The catalyst was separated. After removing the solvent, the residue was crystallised from isopropanol

trans-2-( trans-4-Propylcyclohexyl)-5-(4-fluorophenyl)cyclohexanone (6a). Yield 82\%. m.p. $107^{0} \mathrm{C}$. MS (70 eV) m/z (\%): 316 (M , 51); 272 (90), 191 (15), 179 (15), 164 (5), 148 (25), 135 (40), 122 (90), 109 (95), 95 (25), 81 (25), 67 (30), 55 (35), 41 (50), 29 (10). 
trans-2-( trans-4-Propylcyclohexyl)-5-(4-methoxyphenyl)cyclohexanone (6b). Yield 72\%. m.p. $105^{0} \mathrm{C}$. MS (70 eV) m/z (\%): 328 (M , 80); 300 (15), 284 (100), 175 (25), 147 (65), 134 (85), 121 (55), 91 (15), 55 (7), 41 (12), 29 (5). Purity (GC) > 98\%. Anal. Calcd for $\mathrm{C}_{22} \mathrm{H}_{32} \mathrm{O}_{2}$ : C 80.49, H 9.76. Found: C 80.64, H 9.85.

\section{1-Fluoro-2-(4-substituted phenyl)-5-(trans-4-alkylcyclohexyl)cyclohex-1-ene (17). General procedure}

a. 2-(trans-4-Alkylcyclohexyl)-5-(4-fluorophenyl) cyclohexanone (20 mmol) has been dissolved in $100 \mathrm{ml}$ of benzene and $4.8 \mathrm{~g}$ (30 mmol) of DAST was then added. The reaction mixture was refluxed during $10 \mathrm{~h}$ and after cooling was poured in aqueous solution of $\mathrm{KOH}$. The organic layer was washed with water and dried over sodium sulphate. After removing of benzene the residue was solved in hexane and filtered through aluminium oxide to remove coloured impurities. The obtained crude product contained about $75 \%$ of gem-difluoroderivative $\mathbf{1 6}$ and 25\% of mono-fluoroderivative: 1-fluoro-2-(4-fluorophenyl)-5-(trans-4-alkylcyclohexyl) cyclohex-1-ene 17. b. The product prepared as described above has been mixed with $75 \mathrm{ml}$ of ethylene glycol and $1 \mathrm{~g}$ of $\mathrm{KOH}$. The reaction mixture was boiled under stirring slowly (during 8-10 h) distilling out the solvent. After removing of the part of solvent the residue was cooled, diluted with hexane and washed with diluted hydrochloric acid and then with water. The hexane solution was filtered through column with aluminium oxide or silica gel and after evaporating of solvent the residue was twice crystallised from ethanol. The yield was about $25 \%$ relating to starting saturated cyclohexanone.

1-Fluoro-2-(4-fluorophenyl)-5-(trans-4-propylcyclohexyl)cyclohex-1-ene (17a). Yield 25\%. m.p. $33^{0} \mathrm{C}$. MS (70 eV) m/z (\%): 318 (M , 51); 192 (15), 175 (20), 166 (100), 151 (25), 133 (25), 109 (45), 95 (10), 81 (17), 67 (21), 55 (25), 41 (50), 29 (12). Purity (GC) > 98\%. Anal. Calcd for $\mathrm{C}_{21} \mathrm{H}_{28} \mathrm{~F}_{2}$ : C 79.24, H 8.80. Found: C 79.42, H 9.01.

1-Fluoro-2-(4-methoxyphenyl)-5-(trans-4-propylcyclohexyl)cyclohex-1-ene (17b). Yield 25\%. m.p. 56 C. MS (70 eV) m/z (\%): 330 (M , 100); 204 (7), 178 (75), 163 (15), 147 (20), 135 (10), 121 (12), 115 (7), 55 (15), 41 (20), 29 (5). Purity (GC) > 98\%. Anal. Calcd for $\mathrm{C}_{22} \mathrm{H}_{31} \mathrm{FO}$ : C 80.00, H 9.39. Found: C 80.17, H 9.54.

1-Fluoro-2-(4-methoxyphenyl)-5-(trans-4-pentylcyclohexyl)cyclohex-1-ene (17d). Yield 24\%. m.p. $53^{0}$ C. Purity (GC) >98\%. Anal. Calcd for $\mathrm{C}_{24} \mathrm{H}_{35}$ FO: C 80.45, H 9.78. Found: C 80.66, H 9.93.

trans-5-(trans-4-Propylcyclohexyl)-2-[2-(4-acetylphenyl)ethyl]cyclohexanone (21). trans-5(trans-4-Propylcyclohexyl)-2-(2-phenylethyl) cyclohexanone 9 (41 mmol) in $50 \mathrm{ml}$ of dry methylene chloride was slowly added to the complex prepared from acetyl chloride (45 mmol) and anhydrous aluminium chloride $(86 \mathrm{mmol})$ in $100 \mathrm{ml}$ of the same solvent. The temperature was not allowed to exced $10-15^{\circ} \mathrm{C}$. The reaction mixture was stirred during $2 \mathrm{~h}$ at $15-20^{\circ} \mathrm{C}$ and then decomposed with cold diluted hydrochloric acid. The organic layer was separated, washed with water and then dried over anhydrous magnesium sulphate. After removing solvent, the 
residue was dissolved in ethanol and boiled for $30 \mathrm{~min}$ with $1 \mathrm{~g}$ of charcoal and then, after filtering, twice recrystallized from ethanol; the yield was 54\%. Transitions temperatures: $\mathrm{Cr} 88 \mathrm{~N}$ 170 I $\left({ }^{0} \mathrm{C}\right)$

trans-5-(trans-4-Propylcyclohexyl)-2-[2-(4-ethylphenyl)ethyl]cyclohexanone (22). A solution of trans-5-(trans-4-propylcyclohexyl)-2-[2-(4-acetylphenyl)ethyl]cyclohexanone (5 g) in $50 \mathrm{ml}$ of acetic acid and THF $(1: 1 \mathrm{v} / \mathrm{v})$ was hydrogenated at normal pressure in the presence of $0.5 \mathrm{~g}$ of $10 \%$ palladium on carbon at $30-40^{\circ} \mathrm{C}$ with vigorous stirring until hydrogen was no longer absorbed. The catalyst was separated by filtration and the solvent removed by distillation under reduced pressure. The residue was crystallised from ethanol; the yield + was $88 \%$; Transitions temperatures: r.t. $\mathrm{S}_{\mathrm{B}} 162 \mathrm{I}\left({ }^{0} \mathrm{C}\right)$.

4-(trans-4-Propylcyclohexyl)-1-[2-(4-ethylphenyl)ethyl]cyclohex-1-ene (23). A mixture of $0.02 \mathrm{~mol}$ of trans-5-(trans-4-propylcyclohexyl)-2-[2-(4-ethylphenyl)ethyl]cyclohexanone 22, $0.02 \mathrm{~mol}$ sodium borohydride and isopropyl alcohol $(100 \mathrm{ml})$ was stirred at $50-60^{\circ} \mathrm{C}$ during $8 \mathrm{~h}$. The reaction mixture was then acidified with $10 \%$ hydrochloric acid and the organic layer extracted with ether. The ethereal extract was washed with water and dried over anhydrous magnesium sulphate. The solvent was removed in vacuo and the alcohol was dissolved in $25 \mathrm{ml}$ of pyridine and $5 \mathrm{ml}$ of phosphorous oxychloride added. The reaction mixture was heated at reflux during $5 \mathrm{~h}$ and then poured into water. The product was extracted into ether and washed with water. After removing of ether, the the product was isolated by chromatography on silica gel using hexane as eluent and purified additionally, after removing of the solvent, by recrystallization from isopropyl alcohol Yield $42 \%$; Transitions temperatures: r.t. Sm $74^{\circ} \mathrm{C}$. Purity (GC) $>98 \%$. Anal. Calcd for $\mathrm{C}_{23} \mathrm{H}_{38}$ : C 87.90, H 12.10. Found: C 87.68, H 12.29.

Similar methods gave the other compounds $(\mathbf{1 6}, \mathbf{1 7}, \mathbf{1 8}, \mathbf{2 0}, \mathbf{2 3})$ presented in tables 1 - 3.

\section{References}

1. Plach, H.; Bartmann, E.; Poetsch, E.; Naemura,S.; Rieger, B. SID Digest 1992, 13.

2. Osman, M. A.; Revesz, L. Mol. Cryst. Liq. Cryst. 1982, 82, 41.

3. Demus, D.; Goto, Y.; Sawada, S.; Nakayama, E.; Saito, H.; Tarao, R. Mol. Cryst. Liq. Cryst. 1995, 260, 1

4. Guy, S. C. Display 1993, 13, 32.

5. Eidenschink, R. Mol. Cryst. Liq. Cryst. 1983, 94, 119.

6. Bezborodov, V. S.; Dabrowski, R. Mol. Cryst. Liq. Cryst. 1997, 299, 1

7. Bezborodov, V. S.; Dabrowski, R.; Sasnouski, G.; Dziaduszek, J.; Petrov, V. F. Liq Cryst. 1998, 24, 647

8. Bezborodov, V. S.; Dabrowski, R.; Dziaduszek, J.; Petrov, V. F. Liq Cryst. 1997, 23, 69

9. Sasnouski, G.; Bezborodov, V. S.; Dabrowski, R.; Dziaduszek, J. Mol. Cryst. Liq. Cryst. 1999, 332, 227

10. Bezborodov, V. S.; Petrov, V. F. Liq Cryst. 1999, 26, 271 
11. Kulinkovich, O.; Sviridov, S. V.; Vasilevski, D. A. Synthesis 1991, 234 